\title{
Re-design of a blood supply chain organization with mobile units
}

\author{
Ilker Karadağ ${ }^{1}$ (D) Muhammed Emre Keskin ${ }^{1}$ (D) Vecihi Yiğit ${ }^{1}$ (1) \\ Published online: 18 February 2021 \\ (C) The Author(s), under exclusive licence to Springer-Verlag GmbH, DE part of Springer Nature 2021
}

\begin{abstract}
This research analyses the re-organization of a blood supply chain organization. Blood supply chain network design is a hard problem. Uncertainties of the blood supply and demand, perishability of blood over time and compatibility of blood types are some factors that make the problem difficult. This paper presents a novel multi-objective mixed-integer locationallocation model for a blood supply chain design problem. Unlike many studies on blood supply chain design in the literature, supply chain network consisting of mobile and permanent units is planned together effectively with our mixedinteger programming model. Multi-objective structure of the model minimizes distances between the blood supply chain elements and the length of the mobile unit routes. The objectives are prioritized by experts using the Analytical Hierarchical Process. Finally, the model is implemented on a real life case study using real data from the Eastern Anatolia region of Turkey for various supply demand scenarios. The solutions offered by the model are compared with the current situation in the region. It is shown that the proposed model gives at least $\% 25$ more effective solutions. Moreover, sensitivity analysis on the budget constraint is conducted, and robustness of the model is empirically illustrated.
\end{abstract}

Keywords Blood supply chain · Blood · Humanitarian supply chain management · Mixed-integer programming

\section{Introduction}

Blood is a vital fluid that can deteriorate quickly which makes the development of precise blood supply chains a fundamental issue. Blood supply chains are systems that carry out the activities of collecting blood from donors, processing in laboratories, producing, storing and distributing blood products to the people in need. In this regard, blood supply chains can be considered as a human supply chain. Uncertainties in demand and supply, and the fact that blood is a vital and perishable product, make it difficult to design and plan effective and efficient blood supply chains.

\section{İlker Karadağ}

ilker.karadag@atauni.edu.tr

Muhammed Emre Keskin

emre.keskin@atauni.edu.tr

Vecihi Yiğit

vyigit@atauni.edu.tr

1 Department of Industrial Engineering, Atatürk University, 25240 Erzurum, Turkey
Blood supply chain organization design is actually a humanitarian supply chain management design. Issues such as pricing and decision effort management (Chen et al. (2017), Wang et al. (2020)), optimal contract design (Xiao et al. (2020)) are important in classical supply chain management. Unlike other classical supply chain management systems, the purpose of humanitarian supply chain management systems is to benefit humanity sustainably. For this reason, it is necessary to design blood supply chains effectively and efficiently. In the Republic of Turkey, blood supply chain management solely belongs to the Turkish Red Crescent. The Turkish Red Crescent has an existing blood supply chain in the country. However, it has not been questioned until now how effective and efficient the current system is. The question is, if the system had been designed with operations research techniques, how strong would it be compared to the current system? We are aiming to reply that question by this study and enlight the way for the decision makers for the new investments in the blood supply chain. It is quite difficult and complex to design, establish and manage a blood supply chain system from scratch. Though, considering the new investments to be made in the current supply chain, the proposed model in 
the study can be useful and guide blood supply chain decision makers.

Turkish Red Crescent is an important and complementary part of the international health system. It is the only legal authority recognized by Republic of Turkey Ministry of Health for the collection, distribution, storage and production of blood and blood products. Figure 1 illustrates the supply chain structure of the Turkish Red Crescent, which is responsible for the Turkish Blood Supply Chain. Blood collected from donors through Mobile Blood Donation Vehicle (MBDV) or Blood Donation Center (BDC) is transported to the closest Regional Blood Center (RBC) they are connected to. RBCs process various laboratory operations, produce and stock blood products and the products obtained are transferred to demand points such as hospitals and health centers in amount of their demands. BDCs are units that are smaller compared to RBCs in terms of size, function and capacity, usually in the form of stores in city centers. Donors can donate blood within the relevant working hours. On the other hand, MBDVs travel to donors to collect the donated bloods. RBCs take blood collected by BDCs and MBDVs and undergo various medical laboratory procedures and produce blood products such as platelets, red blood cells and plasma.

Uncertainties in demand and supply in blood supply chains are handled mainly as stochastic optimization problems in Gunpinar and Centeno (2015), Ensafian et al. (2017), Dillon et al. (2017), Zahiri et al. (2018), Hamdan and Diabat (2020a, b) and as robust optimization problems

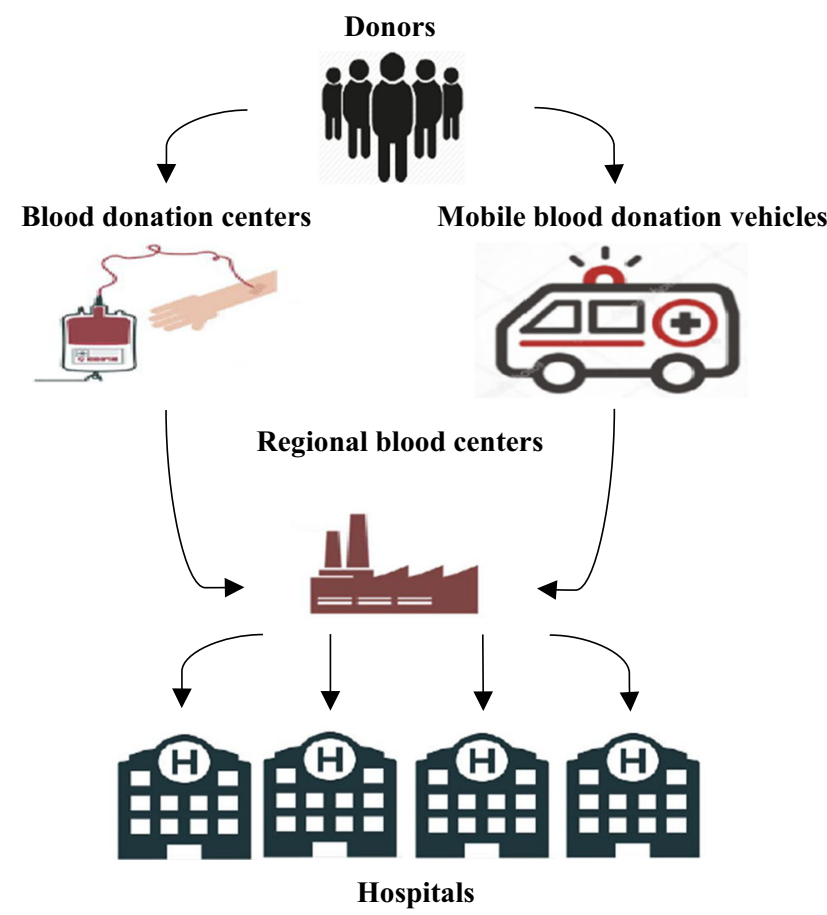

Fig. 1 Turkish Red Crescent Blood Supply Chain Framework in Zahiri et al. (2015), Ramezanian and Behboodi (2017), Ensafian and Yaghoubi (2017), Heidari-Fathian and Pashandideh (2018), Jafarkhan and Yaghoubi (2018), Diabat et al. (2019). In addition, the blood supply chain problem is in the form of fuzzy linear optimization in Zahiri and Pishvaee (2017), Eskandari-Khanghahi et al. (2018), Samani and Hosseini-Motlagh (2019). In our study, demand and supply are estimated based on the historical data, and scenarios are created accordingly.

There are 6 goals that we aim to reach in this study for the design of the blood supply chain organization: (1) determining the number and locations of RBCs, (2) determining the demand points that RBCs will serve, (3) determining the number and positions of BDCs, (4) determining the assignment of BDCs to RBCs, (5) determining the number and route of MBDVs, (6) determining the assignment of MBDVs to RBCs. Thus, we develop a multi-objective mixed-integer mathematical model and we solve it for a real case study with different scenarios. We show that our approach is robust in the sense that the optimal solution remains the same for varying scenario parameters.

There are 5 sections in our study. In Sect. 1, the problem is introduced. In Sect. 2, there is a comprehensive literature research. The formal definition of the problem and the mathematical formulation of the proposed model are given in Sect. 3. In Sect. 4, the results of the mathematical model for the actual data obtained from East-Anatolian region of Turkey are explained. In the last section, the obtained results are evaluated and possible research aspects for future studies are discussed.

\section{Literature survey}

Blood supply chain management, which is a special area of humanitarian supply chain management, is increasingly becoming popular among researchers. There are 4 literature survey of the studies related to the blood supply chains. These are Nahmias (1982), Beliën and Forcé (2012), Osorio et al. (2015) and Pirabán et al. (2019). Nahmias (1982) does not take into account the blood supply and its components and elaborate the studies that take blood as a perishable product. Beliën and Forcé (2012)'s point of view focuses on inventory management, distribution and scheduling in the blood supply chain. Osorio et al. (2015) categorize the models of the studies based on operational processes and model parameters. The recent literature review by Pirabán et al. (2019) analyses the models and methods especially from the recent studies. The study reveals that $57.69 \%$ of the literature occurred after 2015 , and the studies are categorized in a more detailed manner compared to the previous literature surveys. 
The blood supply chain literature focuses on inventory management and distribution of blood and/or blood products. The degradability of blood over time requires careful planning and control of blood inventory management. One of the oldest studies on this subject is done by Prastacos (1984). The study offers applying tools of operations research to blood inventory management theory and practice, and provides an insight into new areas of study for further research. In a similar study, Karaesmen et al. (2011) provide an overview of perishable products. The study accepts blood as a perishable product and elaborates studies on inventory management and points out possible future research topics. Various studies are related to the inventory management in blood banks and hospitals. For instance, Abdulwahab and Wahab (2014) develop a dynamic programming model for blood platelets with a short shelf life that takes into account $\mathrm{ABO}$ blood group compatibility for inventory in blood banks. Duan and Liao (2014) present a new simulation optimization approach that takes $\mathrm{ABO}$ blood group compatibility into consideration for red blood cells (erythrocytes) with a long shelf life. The authors determine near optimal inventory policies based on a new meta-heuristic optimization algorithm. Another study is due to Gunpinar and Centeno (2015) in which a stochastic programming model is proposed for the first time against the uncertainty inherent in the blood demand that minimizes the total cost, the absence of blood product, and the amount of idle blood product throughout a planning horizon. An inventory policy that reduces the amount of out-of-date products during the absence of blood product is proposed by Wang and Ma (2015). The age-related inventory policy of the developed product is analysed by several what-if scenarios and the sensitivity of various parameters are also analysed. A combined inventory policy based on age and stock is presented by Lowalekar and Ravichandran (2017). Dillon et al. (2017) contribute to blood product inventory management. They propose a twostage stochastic programming model that takes into account uncertainty in demand and degradability of the product over time. Najafi et al. (2017) present a multiobjective mixed-integer programming model for blood inventory management in a hospital blood bank, while taking the uncertainty in demand and supply into account. The model minimizes the total cost, the absence of blood product and the amount of idle blood product throughout a planning horizon.

Inventory management for the flow of blood and/or blood products in the supply chain is another important subject study in the literature. Ensafian et al. (2017), Ensafian and Yaghoubi (2017), Osorio et al. (2017), Hosseinifard and Abbasi (2018), Clay et al. (2018), Hosseinifard et al. (2020) can be shown as recent examples. In addition, Ghandforoush and Sen (2010), Şahinyazan et al.
(2015), Blake et al. (2015), Gunpinar and Centeno (2016), Elalouf et al. (2018) focus on the logistics of blood products in the supply chain. The status of the blood supply chain network design and optimization after any disaster and emergency situations is also a sub-area. The changes in the supply chain after the disaster and the optimum strategies to be followed are examined in this sub-study area. Jabbarzadeh et al. (2014), Fahimnia et al. (2017), Samani et al. (2018), Glasgow et al. (2018), Diabat et al. (2019), Fazli-Khalaf et al. (2019), Sharma et al. (2019), Salehi et al. (2019), Rahmani (2019), Khalilpourazari and Khamseh (2019), Haghjoo et al. (2020), Hamdan and Diabat (2020a, b), Wang and Chen (2020) are current examples on this topic.

In this study, we address the blood supply chain network design and optimization problem. We analyse similar studies below. First, Or and Pierskalla (1979) are the pioneering research that addresses the problem of locationallocation in blood supply chain management. A model that minimizes total transportation and system costs is developed in the blood supply chain consisting of hospitals and blood banks. In his handbook, Pierskalla (2004) examines the blood supply chain management from a general perspective. He discusses the hierarchical structure of blood supply chains, inventory management and network design. One of the important studies that address the problem of location-allocation is due to Şahin et al. (2007) in which three mixed-integer mathematical sub-models are proposed. The pq-median location model minimizes the distance between the facilities. The second model keeps the facilities to be opened at a certain distance. The third model is for the homogeneous distribution of mobile units in the service areas. Another important example following this study is pursued by Çetin and Sarul (2009). A non-linear goal programming model is developed to determine the locations and number of blood banks to be placed between hospitals, minimizing the total distance to supply and demand points. Another important example that will be the key to current studies in the literature is due to Nagurney et al. (2012). In this study, unlike previous studies, blood perishability, waste/disposal costs, uncertainties in demand and costs arising from these uncertainties are taken into account. A significant part of the recent literature has followed this study. Zahiri et al. (2015) present a mixed-integer linear programming model by applying a robust probabilistic programming approach to eliminate the uncertainty in model parameters. A similar study is made by Arvan et al. (2015). In addition to cost minimization in the objective function of the proposed model, the time remaining before consumption in the supply chain of blood and blood products is minimized. Zahiri and Pishvaee (2017), on the other hand, prepare a network design study considering the compatibility between blood groups. The 
mathematical model proposed for network design consists of minimum cost with maximum demand satisfaction. Ramezanian and Behboodi (2017) aim to eliminate uncertainty in supply chain parameters using the robust optimization approach. The study is the first article to investigate the role of blood donors on decision variables in blood supply chain design, according to the authors' claims. Masoumi et al. (2017) examine the merger of two different blood supply chain organizations, unlike the studies in the literature. With the mathematical model they propose, performance criteria such as cost efficiency, product absence and product excess are improved. HeidariFathian and Pasandideh (2018) work on green blood supply chain design and propose a Lagrange relaxation approach to solve the mixed-integer mathematical model they propose. Eskandari-Khanghahi et al. (2018) propose a multiobjective stochastic optimization model for a sustainable blood supply chain design. The solution for large-scale problems in the study is provided by simulated annealing. Zahiri et al. (2018), with their multi-objective mixed-integer programming model, offer a priority queue system for blood product congestion in each hospital and a new metaheuristic solution is developed for large-scale problems. Bruno et al. (2019) reposition the supply chain facilities in a region of interest. They prove that their model can be used as a decision support system with several scenarios. Hamdan and Diabat (2019) design a blood supply chain with a two-step multi-objective stochastic optimization model. While the number of mobile units is determined in the first stage, inventory and production decisions are determined in the second stage. Hosseini-Motlagh et al. (2020) develop a bi-objective two-stage stochastic programming model for managing a red blood cells supply chain that observes blood group compatibility. The proposed model determines the optimum location-allocation and inventory management decisions and aims to minimize the total cost of the supply chain including fixed costs, operating costs, inventory holding costs, wastage costs and transportation costs along with minimizing the substitution levels to provide safer blood transfusion services. Finally, Hamdan and Diabat (2020a, b) propose a novel approach to deal with the issue of solving large operational stochastic optimization problems by using machine learning models.

As a result of the general literature review, the contributions of our study to the literature can be summarized in the following;

- The blood supply chain we examine has 4 echelons. These are RBCs, BDCs, MBDVs and supply/demand points. RBCs perform all the duties of the laboratories, storage facilities and distribution centers in the supply chains (Nagurney et al. (2012) and Zahiri et al. (2015)). BDCs are fixed units that collect blood donations and are connected to RBCs. MBDVs are mobile units that collect blood in the supply chain and transfer the collected blood to RBCs. They serve at locations where $\mathrm{RBCs}$ and BDCs are not available or where capacity is not sufficient. Our aim is to determine the number and locations of facilities that can meet the needs of supply demand points.

- The proposed model is a multi-objective mixed-integer mathematical model. Unlike the objective function of the mathematical models in the literature, the objective function minimizes the distance of the supply chain components with each other, as well as the total length of the route of the mobile elements. Similar models in the literature generally deal with cost minimization as an objective function.

- We address the blood supply chain problem from an integrated perspective, not just a location-allocation problem or just a route planning of mobile units' problem. Therefore, as much as we are concerned with the positioning of the permanent units, we are also interested in the routes that mobile units should follow.

- Different purposes in the objective function are evaluated by experts using the Analytical Hierarchical Process (AHP) and their priority coefficients are determined. The objective function takes into account the minimum transport time, minimum cost directly and product shelf lives, indirectly.

- The model is tested for a real data set obtained from the East-Anatolian region of Turkey. It is shown that the efficiency of the existing blood supply chain can be improved significantly by the help of the offered model.

- By addressing the supply chain in a developing region, the model is intended to contribute to the new investments to be made. Theoretical and practical outputs are provided to supply chain decision makers for possible future investments.

\section{Multi-objective mixed-integer mathematical model}

In this section, the multi-objective mixed-integer mathematical model is explained. First of all, the problem specifications are given. Then, notation and formulation of the mathematical model are introduced.

\subsection{Problem statement}

The content of this problem includes locating RBCs, BDCs and MBDVs positions, determining the optimum number of units which is used and determining the allocations between them. As mentioned above, the model possesses a 
holistic perspective. Namely, we minimize the distances between the units of the blood supply chain and at the same time, we minimize the travel lengths of the mobile units.

The assumptions we make about the problem specifications are as follows;

- The capacity of each RBC is known.

- The capacity of each BDC is known.

- The capacity of each MBDV is known.

These assumptions are made due to the fact that the RBCs, BDCs and MBDVs, which are in the supply chain of the Red Crescent, mostly have the same type and equal capacity and it is therefore natural to assume known capacities.

- Opening and operating costs of RBC, BDC and MBDV vary by location and they are all known.

- RBCs can be found in locations with a population of 400 thousand and above.

- BDCs can be found in locations with a population of 100 thousand and above.

- Each BDC that is opened is assigned to a single RBC.

- Each MBDV that is opened is assigned to a single RBC.

These assumptions comply with the cost/settlement structures of the real Red Crescent units that are already known in advance.

- Donors are distributed homogeneously in the population and bounded.

- Demands are distributed homogeneously in the population and bounded.

These two assumptions are commonly made in the literature (i.e., Ensafian and Yaghoubi (2017), Arvan et al. (2015), Şahinyazan et al. (2015), Jabbarzadeh et al. (2014)). Hence, we also resort to homogeneity assumptions. Moreover, studies reveal that imbalance between the different regions of Turkey tend to decrease in every aspect in recent years which can be seen as a justification for our usage of these assumptions.

\subsection{Mathematical model}

\subsubsection{Model notation}

The notation to be used in the proposed model is as follows;

\subsubsection{The formulation}

In the proposed model, the objective function takes into account three different sections. The first part of the objective function is the distance between BDCs and RBCs (A), the second part is the distance between RBCs and demand points (B) and the third part is the length of the routes that MBDVs will follow for blood collection (C). However, the importance of these objectives is undoubtedly different from each other. In this regard, the goals are evaluated by three experts who have experience and knowledge on the subject. We choose Analytical Hierarchical Process (AHP) which is developed by Saaty (1990) as the evaluation method since it is simple and practical to use and still considered to be quite effective. AHP uses binary comparison matrices to determine weights, using a scale from 1 to 9 in these comparisons. It takes the value 9 if one goal is of much more important than the other, and 1 if it is of equal importance. However, depending on the degree of importance, intermediate values of 3,5 and 7 can also be given by the decision maker. Binary comparison matrices are square matrices, their diagonal values are 1, and the comparison of goals is made exactly and mutually according to the degree of importance they have (Tables 1, 2 and 3).

After the goals included in the objective function are named as A, B, C, respectively, the decision makers are asked to evaluate them in the criterion of the "total cost that will create in the supply chain". Table 4 is the binary comparison matrix of one of the decision makers. These comparison values are then normalized first by the column totals, and then, weights of the rows are calculated to find the weight values. The average of the weight values obtained from three decision makers in the decision making team are 0,409, 0,386 and 0,204, respectively. Minimizing the distance between the RBCs and demand points is represented by the decision-making team with the highest weight value. The RBC is very costly in terms of investment and investment decision is more important than other purposes since it is strategically important. The objective function is formulated accordingly. The mixedinteger linear programming formulation is given below:

$$
\begin{aligned}
& \text { Min 0, } 409 \sum_{i \in I} \sum_{j \in J}\left(d_{i j}^{1} u_{i j}^{1}\right)+0,386 \sum_{j \in J} \sum_{k \in K}\left(d_{j k}^{2} u_{j k}^{2}\right) \\
& +0,204 \sum_{l \in L} \sum_{k \in K} \sum_{m \in K}\left(d_{\mathrm{km}}^{3} \beta_{\mathrm{lkm}}\right)
\end{aligned}
$$

Subject to

Table 1 Sets and indices

\begin{tabular}{ll}
\hline Sets & Description \\
\hline$I / i$ & Set of BDC candidate points and its index \\
$J / j$ & Set of RBC candidate points and its index \\
$K / k, m$ & Set of supply/demand points and its indices \\
$L / l$ & Set of MBDVs and its index \\
\hline
\end{tabular}


Table 2 Parameters

\begin{tabular}{ll}
\hline Parameters & Description \\
\hline$A_{k}$ & Supply of point $k$ \\
$D_{k}$ & Demand of point $k$ \\
$c_{i}^{1}$ & Capacity of BDC to be opened at point $i$ \\
$c_{l}^{2}$ & Capacity of the $l^{\text {th }}$ MBDV \\
$c_{j}^{3}$ & Capacity of RBC to be opened at point $j$ \\
$d_{i j}^{1}$ & Distance between BDC at point $i$ and $\mathrm{RBC}$ at point $j$ \\
$d_{\mathrm{jk}}^{2}$ & Distance between RBC at point $j$ and demand point $k$ \\
$d_{\mathrm{km}}^{3}$ & Distance between demand/supply point $k$ and demand/supply point $m$ \\
$d_{\mathrm{ki}}^{4}$ & Distance between demand/supply point $k$ and BDC at point $i$ \\
$F$ & Total allocated budget \\
$f_{i}^{1}$ & Total cost of locating a BDC at point $i$ \\
$f_{j}^{2}$ & Total cost of locating an RBC at point $j$ \\
$f_{l}^{3}$ & Total operating cost of operating $l^{\text {th }}$ MBDV \\
$\gamma_{k}$ & 1 if $k$ demand point is also an RBC point, otherwise 0 \\
$\varphi_{k}$ & 1 if $k$ supply point is also an BDC point, otherwise 0 \\
\hline
\end{tabular}

Table 3 Decision variables

\begin{tabular}{ll}
\hline Variables & Description \\
\hline$p_{i}$ & 1 if an BDC is opened at point $i$, otherwise 0 \\
$r_{j}$ & 1 if an RBC is opened at point $j$, otherwise 0 \\
$s_{l}$ & 1 if $l$ th MBDV is used, otherwise 0 \\
$u_{i \mathrm{j}}^{1}$ & 1 if BDC at point $i$ is assigned to RBC at point $j$, otherwise 0 \\
$u_{\mathrm{jk}}^{2}$ & 1 if demand/supply point $k$ is assigned to RBC at point $j$, otherwise 0 \\
$u_{\mathrm{lj}}^{3}$ & 1 if $l$ th MBDV is assigned to RBC at point $j$, otherwise 0 \\
$u_{\mathrm{ki}}^{4}$ & 1 if demand point $k$ is assigned to BDC at point $i$, otherwise 0 \\
$x_{k}^{1}$ & Amount of blood collected at BDC from supply point $k$ \\
$x_{k l}^{2}$ & Amount of blood collected from $l$ th MVDV from supply point $k$ \\
$y_{\mathrm{ij}}^{1}$ & Amount of the supply transferred from BDC at point $i$ to RBC at point $j$ \\
$y_{\mathrm{lj}}^{2}$ & Amount of the supply transferred from $l$ th MBDV to RBC at point $j$ \\
$z_{\mathrm{jk}}$ & Amount of blood transferred to demand point $k$ by RBC at point $j$ \\
$\theta_{\mathrm{kl}}$ & 1 if $k$ demand point takes service from $l$ th MBDV, otherwise 0 \\
$\beta_{\mathrm{lkm}}$ & 1 if $l$ th MBDV goes from demand point $\mathrm{k}$ to demand point $m$, otherwise 0 \\
$v_{k l}$ & The order of the arrival of $l$ th MBDV to the demand point $k$ \\
\hline
\end{tabular}

Table 4 Binary Comparison matrix

\begin{tabular}{lllll}
\hline & A & B & C & Weight \\
\hline A & 1,000 & 5,000 & 0,333 & 0,574 \\
B & 0,200 & 1,000 & 3,000 & 0,286 \\
C & 3,000 & 0,333 & 1,000 & 0,140 \\
\hline
\end{tabular}

$\sum_{j=1}^{J} u_{i j}^{1}=p_{i} \quad i \in I$

$u_{i j}^{1} \leq r_{j} \quad i \in I, j \in J$ 
$\sum_{i=1}^{I} p_{i} f_{i}^{1}+\sum_{j=1}^{J} r_{j} f_{j}^{2}+\sum_{l=1}^{L} s_{l} f_{l}^{3} \leq F$

$\theta_{k l}=\sum_{m \in K} \beta_{\mathrm{lkm}} \quad k \in K, l \in L$

$\sum_{k \in K} \beta_{\mathrm{ljk}}=u_{\mathrm{lj}}^{3} \quad j \in J, l \in L$

$\sum_{k \in K} \beta_{\mathrm{lkj}}=u_{l j}^{3} \quad j \in J, l \in L$

$\sum_{k \in K} \sum_{m \in K} \beta_{\mathrm{lkm}} \leq s_{l}|K|^{2} \quad l \in L$

$\sum_{k \in K} \beta_{\mathrm{lkm}}=\sum_{k \in K} \beta_{\mathrm{lmk}} \quad l \in L, m \in K$

$v_{\mathrm{kl}}-v_{\mathrm{ml}}+|K| \beta_{\mathrm{lkm}} \leq|K|-1$

$k \in K, l \in L, m \in K: \gamma_{k} \neq 1, \gamma_{m} \neq 1, k \neq m$

$x_{k}^{1}+\sum_{l=1}^{L} x_{\mathrm{kl}}^{2} \leq A_{k} \quad k \in K$

$x_{k}^{1} \leq c_{k}^{1} p_{k} \quad k \in K: \varphi_{k}=1$

$\sum_{k=1}^{K} x_{\mathrm{kl}}^{2} \leq c_{l}^{2} \quad l \in L$

$x_{\mathrm{kl}}^{2} \leq c_{l}^{2} \theta_{\mathrm{kl}} \quad k \in K, l \in L$

$\sum_{i \in I} y_{\mathrm{ij}}^{1}+\sum_{l \in L} y_{\mathrm{lj}}^{2} \leq c_{j}^{3} \quad j \in J$

$y_{\mathrm{ij}}^{1} \leq u_{\mathrm{ij}}^{1} c_{j}^{3} \quad i \in I, j \in J$

$y_{l j}^{2} \leq u_{\mathrm{lj}}^{3} c_{j}^{3} \quad j \in J, l \in L$

$x_{k}^{1}=\sum_{j=1}^{J} y_{\mathrm{kj}}^{1} \quad k \in K: \varphi_{k}=1$

$\sum_{k=1}^{K} x_{\mathrm{kl}}^{2}=\sum_{j=1}^{J} y_{\mathrm{lj}}^{2} \quad l \in L$

$$
\sum_{j=1}^{J} z_{\mathrm{jk}}=D_{k} \quad k \in K
$$

$z_{\mathrm{jk}} \leq u_{\mathrm{jk}}^{2} D_{\mathrm{k}} \quad j \in J, k \in K$

$\sum_{i=1}^{I} y_{\mathrm{ij}}^{1}+\sum_{l=1}^{L} y_{\mathrm{lj}}^{2} \geq \sum_{k=1}^{K} z_{\mathrm{jk}} \quad j \in J$

$p_{i}, r_{j}, s_{l}, u_{\mathrm{ij}}^{1}, u_{\mathrm{jk}}^{2}, u_{\mathrm{lj}}^{3}, u_{\mathrm{ki}}^{4}, \theta_{\mathrm{kl}}, \beta_{\mathrm{lkm}} \in\{0,1\}$

$x_{k}^{1}, x_{k l}^{2}, y_{i j}^{1}, y_{l j}^{2}, z_{j k}, v_{k l} \geq 0$
- Constraint (2) connects each BDC to an RBC that is if a $\mathrm{BDC}$ is opened at point $i, p_{i}$ will be 1 on the right hand side of the equation, sum of all RBC connection variables is equated to 1 .

- Constraint (3) is the link between RBC $j$ and BDC $i$, if an $\mathrm{RBC}$ is opened at point $j, r_{j}$ will be 1 and the corresponding variable providing the connection between RBC and BDC which is $u_{i j}^{1}$ may be 1 , otherwise the connection is not provided.

- Constraint (4) connects each demand point to one RBC; the sum of all RBC connections that is connected to the demand point must be 1 .

- Constraint (5) is the link between RBC $j$ and $k$ demand point, if an RBC is opened at point $j, r_{j}$ will be 1 and on the left hand side of the equation the corresponding variable providing the connection between RBC and $k$ demand point may be 1 , otherwise the connection is not provided.

- Constraint (6) connects each used MBDV to one RBC, that is if lth MBDV is used, $s_{l}$ will be 1 and it is assigned to a single RBC as the summation of the assignment variables are equated to 1 .

- Constraint (7) is the link between RBC $j$ and the lth MBDV, if an RBC is opened at point $j, r_{j}$ will be 1 and on the left hand side of the equation, the corresponding variable providing the connection between $\mathrm{RBC}$ and $l$ th MBDV may be 1 , otherwise the connection is not provided.

- Constraint (8) is the budget constraint. The costs of total opening and operating RBCs, BDCs and the MBDVs cannot exceed the total budget allocated by the Turkish Red Crescent.

- Constraint (9) checks whether lth MBDV has visited point $k$ or not.

- Constraints (10) and (11) should be examined together. If $l$ th MBDV is assigned to the RBC at point $j$, then $l^{\text {th }}$ MBDV is forced to start its tour from point $\mathrm{j}$ and to return to point $\mathrm{j}$ by these constraints.

- Constraint (12) prevents movement of lth MBDV if the related variable $s_{l}$ is 0 , and vice versa.

- Constraint (13) ensures that lth MBDV leaves the point that it enters.

- Constraint (14) prevents the formation of sub-tours.

- Constraint (15) guarantees that the total supply collected by the assigned BDC and MBDVs are less than the supply amounts for all points.

- Constraint (16) ensures that the supply transferred to the BDC at point $k$ does not exceed the capacity of the BDC. 
- Constraint (17) ensures that the supply transferred to lth MBDV by the supply points does not exceed the capacity.

- Constraint (18) provides the link between supply point $k$ and lth MBDV. The $\theta_{k l}$ variable will be 1 if supply point $k$ is visited by the $l$ th MBDV so this will create a connection between these units.

- Constraint (19) ensures that the amount coming from the BDCs and MBDVs does not exceed the capacity of the $\mathrm{RBC}$ at point $j$.

- Constraint (20) provides the connection between the BDC at point $i$ and the RBC at point $j$, namely the $u_{i j}^{1}$. variable will be 1 if there is a connection between the BDC point $i$ and the RBC at point $j$. Otherwise, there is no connection.

- Constraint (21) provides the connection between the lth MBDV and the RBC at point $j$. The $u_{l j}^{3}$ variable will be 1 if there is a connection between the lth MBDV and the RBC at point $j$. Otherwise, there is no connection.

Constraint (22) ensures that the amount of donations collected by BDC at point $k$ is equal to the amount transferred it to the RBCs.

- Constraint (23) ensures that the amount of donations collected by $l$ th MBDV is equal to the amount transferred from it to the RBCs.

- Constraint (24) ensures that the RBCs transmit the quantity to the demand points as much as the demands of them.

- Constraint (25) provides the connection between RBCs and the demand points so that the demand point $k$ can be served from the RBC at point $j$. The $u_{j k}^{2}$ variable will be 1 if there is a connection between the demand point $k$ and the $\mathrm{RBC}$ at point $j$. Otherwise, there is no connection.

- Constraint (26) ensures that the amount transmitted from the RBC at point $j$ is less than the amount that is collected and transferred to it.

- Constraint (27) and constraint (28) define the type of decision variables.

\section{Re-design of a real blood supply chain}

This section is devoted to the application of our model to a real life problem from the Eastern Anatolia region of Turkey. Eastern Anatolia region is located in the eastern part of Turkey. Although it is the largest region occupying $21 \%$ of the total area of the country, it is in the last place in terms of population density. Stockbreeding is the major income for the local economy. Agriculture is very limited to wheat, barley, cotton and tobacco. The region has the highest unemployment rate in Turkey. The lowest investments and elements of the Turkish Red Crescent blood supply chain are located in this region. Therefore, it is more appropriate to compare the current system in this region with the proposed model and to evaluate the new investments to be made by blood supply chain decision makers. In the Eastern Anatolia Region of Turkey, there are 14 cities and a total of 122 settlements. The total population is $6,058,529$ as of 2018. 4 RBCs candidate points, 14 BDCs candidate points, 15 MBDVs, 122 supply/demand points are determined in the region. Figure 2 shows the cities in the region. The red dots in the figure indicate RBC candidate points, blue dots indicate BDC candidate points and green dots indicate some of the demand points.

The Red Crescent data of the city centers in the Eastern Anatolia Region are summarized in Table 5. The latest data available in the region to the Turkish Red Crescent belong to 2018. According to Table 5, Red Crescent provides continuous service in 7 cities in the region. Red Crescent does not actively collect blood from other cities and settlements of the region. We will call the cities that Red Crescent actively serves as the active cities and the rest of the cities as the passive cities in the sequel. In addition, due to the lack of data and information, passive cities and settlements have no recorded demand values. The only data available regarding the demand can be deducted from the total amount of products offered by RBCs in the region (Fig. 3).

In order to compare the current situation of the supply chain with the supply chains the model offers for different scenarios, the data for the passive cities and settlements must be generated. Based on the assumption that donors are homogenously located in the settlements of the region and are directly proportional to the population, we determined these missing demand and supply values. First, we find supply coefficients by dividing the supply amounts in the active cities of the region by the populations of the cities. We apply these supply coefficients for the passive cities and settlements assuming that the passive city and settlements have the same blood donation structure with the closest active city. Thus, the potential total supply in the entire region is calculated. We also determine the demand coefficients by dividing the total population of the cities served by each RBC to the total demand of these cities. We apply these demand coefficients for the passive cities and settlements. Thus, potential total demand values in the region for the passive cities/settlements are also calculated according to the closest active city criteria.

In order to evaluate the current situation and to be able to compare it with the supply chains the model offers, we fix the RBC, BDC location variables $(p, r)$ and MBDV usage variables $(s)$ according to the real data obtained from the region. The routes of MBDVs are not known and they 
Fig. 2 Eastern Anatolia Region of Turkey

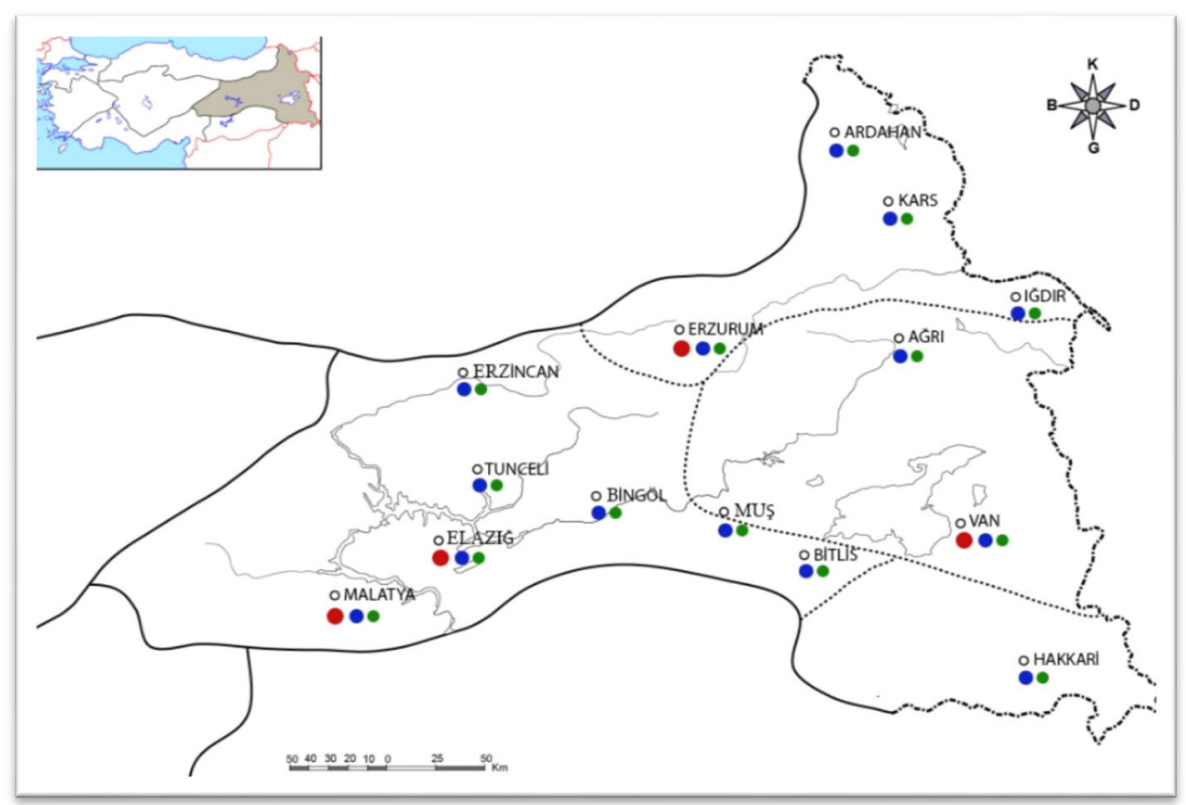

Table 5 Blood Supply Chain Data for Eastern Anatolia Region Cities (2018)

\begin{tabular}{|c|c|c|c|c|c|c|c|}
\hline City & Active/Passive & Population & Supply (Units) & Demand (Units) & Number of RBC & Number of BDC & Number of MBDV \\
\hline Malatya & Active & 600,660 & 32,638 & 102,210 & 1 & 1 & 3 \\
\hline Van & Active & 472,766 & 30,159 & 84,300 & 1 & 1 & 2 \\
\hline Erzurum & Active & 422,164 & 38,011 & 48,813 & 1 & 1 & 4 \\
\hline Elazı̆g & Active & 421,726 & 20,018 & - & 0 & 1 & 2 \\
\hline Muş & Active & 193,394 & 8786 & - & 0 & 1 & 0 \\
\hline Bingöl & Passive & 160,165 & - & - & 0 & 0 & 0 \\
\hline Erzincan & Active & 157,452 & 14,524 & - & 0 & 1 & 2 \\
\hline Ağr1 & Passive & 149,188 & - & - & 0 & 0 & 0 \\
\hline Iğdır & Passive & 137,613 & - & - & 0 & 0 & 0 \\
\hline Kars & Active & 115,891 & 10,017 & - & 0 & 1 & 2 \\
\hline Hakkari & Passive & 81,424 & - & - & 0 & 0 & 0 \\
\hline Bitlis & Passive & 71,501 & - & - & 0 & 0 & 0 \\
\hline Ardahan & Passive & 42,226 & - & - & 0 & 0 & 0 \\
\hline Tunceli & Passive & 38,504 & - & - & 0 & 0 & 0 \\
\hline Total & & 3064674 & 154,123 & 235,323 & 3 & 7 & 15 \\
\hline
\end{tabular}

are taken as decision variables in the model, while the other relevant decision variables are fixed according to the real data. For instance, as there is an RBC at Malatya the relevant $r_{j}$. variable related to Malatya is fixed as 1 and as there is no RBC located at Erzincan, the relevant $r_{j}$ variable related to Erzincan is fixed to 0. Similarly, all the $p, r$ and $s$ variables and the assignment variables between these units are fixed. Only binary variables that are unknown are related to the routes of the mobile units and this is why they are taken as free decision variables in the model. The values of the current situation are summarized in Table 6.
The current supply chain objective function value is about $25 \%$ higher than the objective function value obtained by the proposed model in scenario 1 . In addition, the blood supply chain in scenario 1 serves with fewer units. Besides, while the solutions for scenarios are obtained in $3 \mathrm{~h}$ by the commercial solver Gurobi, it runs for $6 \mathrm{~h}$ to obtain the current situation solution. The effectiveness of the proposed model can be proved when the objective function values obtained in other scenarios are examined. Scenario 1 is our basic scenario where we determine the expected supply and demand amount 
Fig. 3 Flow chart of the proposed supply chain design

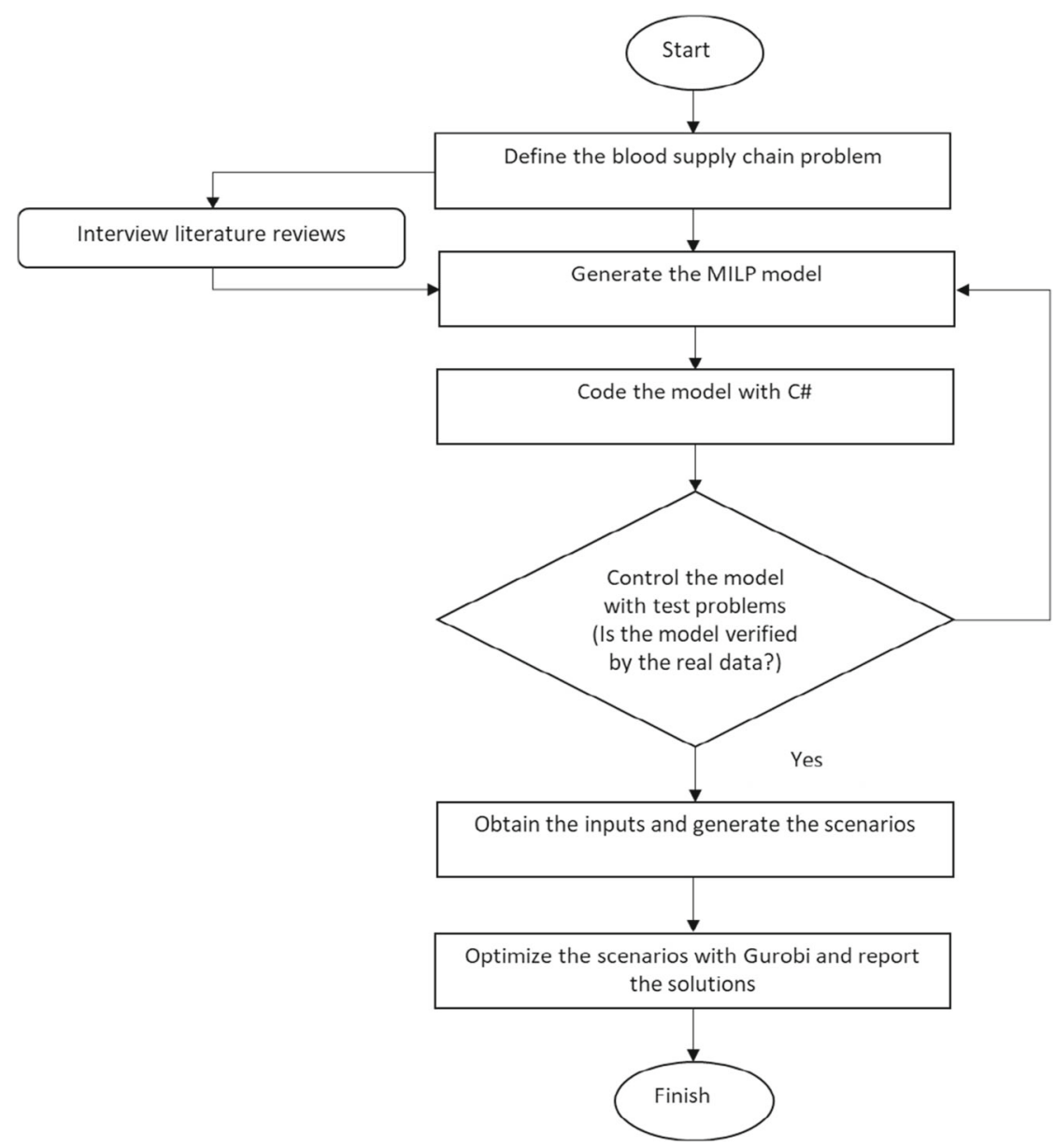

No
Table 6 The structure of the current supply chain

\begin{tabular}{|c|c|c|c|c|}
\hline Objective function value (1) & \multicolumn{4}{|c|}{$13,507,016$} \\
\hline Total supply (2) & \multicolumn{4}{|c|}{390,778} \\
\hline Total demand (3) & \multicolumn{4}{|c|}{336,560} \\
\hline RBCs and their locations (4) & 3 & Malatya & Van & Erzurum \\
\hline BDCs and their locations (5) & 7 & Malatya, Elazı̆̆ & Van, Kars, Mus & Erzurum, Erzincan \\
\hline MBDVs shares (6) & 15 & $5 \mathrm{MBDV}$ & $4 \mathrm{MBDV}$ & $6 \mathrm{MBDV}$ \\
\hline
\end{tabular}

(detailed above) as if Red Crescent actively serves the entire region. Scenario 1 is actually the same with the current situation except that the values of the decision variables are not fixed according to real data. The supply and demand values are changed and different scenarios are created as shown in Table 7. Thus, supply and demand, which are the most important uncertainty sources in the model, are tried to be eliminated with the scenarios created. Scenario 2, 3, 4, 5 and 6 examine the results of the model in case the supply and demand values increase by $20 \%, 40 \%$, $60 \%, 80 \%$ and $100 \%$ with respect to Scenario 1, respectively. Supply and demand values can increase together in disasters such as earthquakes and floods where social sensitivity is at a high level, and in extraordinary situations such as war. Scenarios 7, 8 and 9 examine the results of the model when supply and demand values are reduced by $20 \%, 40 \%$ and $60 \%$, respectively. Supply and demand may decrease together, where there is no social sensitivity and interest, pandemics (i.e., COVID-19) and where the region emigrates. In scenario 10, while supply increased by $20 \%$ compared to scenario 1 , demand values decreased at the same rate.

In the scenarios, we use the parameters of the distance between settlements from Turkey Highways government 
agencies. According to data obtained from Turkish Red Crescent, all RBCs have the same capacity. Similarly, all BDCs capacities and MBDVs capacities are alike. However, the total investment and operating costs of an RBC, a $\mathrm{BDC}$ and an MBDV in the region are calculated and the total allocated budget by the Turkish Red Crescent is determined by considering all the supply chain units in the region. The budget parameter $F$ is determined in this way.

In order to obtain the results of the model according to the scenarios, the model algorithm has been coded in $\mathrm{C} \#$ programming language in Microsoft Visual Studio 2017 environment and it has been solved on the desktop computer with Intel (R) Core (TM) i7-4770 CPU $3.40 \mathrm{GHz}$ processor with the help of Gurobi81.NET solver (Gurobi Optimization (2019)). In general, all the commercial MILP solvers employ Mathematical Programming and Operations Research tools such as branch and bound, generate valid inequalities to add them to branch and bound tree in order to convert it into a branch and cut scheme, etc. However, the exact structure of the branch and cut schemes they use, the valid inequalities they generate are kept hidden due to the commercial concerns. Nonetheless, we still add a flow chart that summarizes our solution approach in a step by step manner below.

The results for the scenarios are summarized in Tables 8, 9, 10, 11, 12, 13, 14, 15, 16 and 17 given below.

As the scenarios are examined, and the following results will be clearly seen. The objective function values are given in (1). Total supply (2) and total demand (3) amounts are the values obtained from the scenarios created. RBCs and their locations (4) show at which of the candidate points the model open or does not open RBCs. In all scenarios, RBCs are located in Malatya, Van, Erzurum and Elazı ğ cities. Consequently, RBC should be opened to Elazı $\breve{g}$ city in addition to the Malatya, Van and Erzurum which are real RBC places. BDCs and their locations are shown by (5). According to the results, cities with RBC should also have a BDC. These BDCs serve depending on RBCs in their cities. MBDVs and their locations (6) show which of the total mobile units determined will serve on which RBCs. MBDVs are positioned with different shares according to the scenarios. As an example, 4 mobile units are assigned to RBC in Erzurum in scenario 1, while 3 mobile units are assigned to Erzurum in scenario 3. This situation also results in the differentiation of routes to be, followed by MBDVs according to the changing supply/ demand structure. According to the scenarios, the route that each MBDV will follow is not given here and can be extracted from the detailed examination of the scenario results. For example, in scenario 1, mobile units visit 117 settlements, while in scenario 2, 111 settlements are visited. The model also reveals in which position each mobile unit should be located. However, the summary results do not include routes.

In Fig. 4, the objective function values of the scenarios are shown against the total units used in the supply chains. It can be seen that the more supply and demand in the system, the more mobile units need to travel or new BDCs need to opened (i.e., scenario 4 and 6), and these affect the objective function. When we move from scenario 1 to scenario 2, total supply and demand increases by $20 \%$. Although more MBDV units are used in Scenario 2, the objective function value decreases slightly due to the settlements with a higher supply of closer locations. Similarly, when we move from scenario 3 to scenario 4, we see that the objective function value decreases. This may be because of the new opened BDC in the system. We observe a similar situation when we move from scenario 5 to scenario 6 as well. In scenarios where there is a decrease in total supply and demand in the system (scenario7, scenario 8 and scenario 9), the number of used MBDV units also decrease. Meanwhile, in all scenario results, it is seen that RBCs are opened in the same cities. The results possess a robust structure in this regard. Therefore, it may be suggested to Turkish Red Crescent to open RBC to Elazı $\breve{g}$ city. When BDC locations are examined, it is also mostly seen that they are opened in the same cities. Hence, the results are robust with respect to $\mathrm{RBC}$ opening decisions as well. However, in only one scenario, which is scenario 6, BDC distribution turns out to be different probably because of very high supply/demand values as we double them in that scenario. MBDVs are assigned with different combinations

Table 7 Scenarios

\begin{tabular}{llllll}
\hline Scenarios & Total Supply (Units) & Total Demand (Units) & Scenarios & Total Supply (Units) & Total Demand (Units) \\
\hline Scenario 1 & 390,778 & 336,560 & Scenario 6 & 781,556 & 673,121 \\
Scenario 2 & 468,993 & 403,872 & Scenario 7 & 312,622 & 269,248 \\
Scenario 3 & 547,089 & 471,184 & Scenario 8 & 234,467 & 201,936 \\
Scenario 4 & 625,245 & 538,497 & Scenario 9 & 156,311 & 134,624 \\
Scenario 5 & 703,400 & 605,809 & Scenario 10 & 468,933 & 269,248 \\
\hline
\end{tabular}


Table 8 Scenario 1 results

Table 9 Scenario 2 results

Table 10 Scenario 3 results

Table 11 Scenario 4 results

Table 12 Scenario 5 results

according to the scenarios. Each different assignment combination brings with it different sub-scheduling problems.

\begin{tabular}{|c|c|c|c|c|c|}
\hline Objective function value (1) & \multicolumn{5}{|c|}{$10,791,432$} \\
\hline Total supply (2) & \multicolumn{5}{|c|}{390,778} \\
\hline Total demand (3) & \multicolumn{5}{|c|}{336,560} \\
\hline RBCs and their locations (4) & 4 & Malatya & Van & Erzurum & Elazı $\breve{g}$ \\
\hline BDCs and their locations (5) & 4 & Malatya & Van & Erzurum & Elazı $\breve{g}$ \\
\hline MBDVs shares (6) & 9 & $1 \mathrm{MBDV}$ & $4 \mathrm{MBDV}$ & $2 \mathrm{MBDV}$ & $2 \mathrm{MBDV}$ \\
\hline
\end{tabular}

\begin{tabular}{|c|c|c|c|c|c|}
\hline Objective function value (1) & \multicolumn{5}{|c|}{$10,288,368$} \\
\hline Total supply (2) & \multicolumn{5}{|c|}{468,933} \\
\hline Total demand (3) & \multicolumn{5}{|c|}{403,872} \\
\hline RBCs and their locations (4) & 4 & Malatya & Van & Erzurum & Elazı $\breve{g}$ \\
\hline BDCs and their locations (5) & 4 & Malatya & Van & Erzurum & 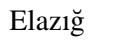 \\
\hline MBDVs shares (6) & 12 & $2 \mathrm{MBDV}$ & $5 \mathrm{MBDV}$ & $3 \mathrm{MBDV}$ & $2 \mathrm{MBDV}$ \\
\hline
\end{tabular}

\begin{tabular}{|c|c|c|c|c|c|}
\hline Objective function value (1) & \multicolumn{5}{|c|}{$11,388,948$} \\
\hline Total supply (2) & \multicolumn{5}{|c|}{547,089} \\
\hline Total demand (3) & \multicolumn{5}{|c|}{471,184} \\
\hline RBCs and their locations (4) & 4 & Malatya & Van & Erzurum & 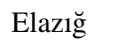 \\
\hline BDCs and their locations (5) & 4 & Malatya & Van & Erzurum & Elazı̆̆ \\
\hline MBDVs shares (6) & 13 & $2 \mathrm{MBDV}$ & $5 \mathrm{MBDV}$ & $3 \mathrm{MBDV}$ & $3 \mathrm{MBDV}$ \\
\hline
\end{tabular}

\begin{tabular}{|c|c|c|c|c|c|}
\hline Objective function value (1) & \multicolumn{5}{|c|}{$10,921,775$} \\
\hline Total supply (2) & \multicolumn{5}{|c|}{625,245} \\
\hline Total demand (3) & \multicolumn{5}{|c|}{538,497} \\
\hline RBCs and their locations (4) & 4 & Malatya & Van & Erzurum & Elazı $\breve{g}$ \\
\hline BDCs and their locations (5) & 5 & Malatya & Van & Erzurum, Erzincan & Elazı $\breve{g}$ \\
\hline MBDVs shares (6) & 13 & $2 \mathrm{MBDV}$ & $6 \mathrm{MBDV}$ & $2 \mathrm{MBDV}$ & 3 MBDV \\
\hline
\end{tabular}

\begin{tabular}{|c|c|c|c|c|c|}
\hline Objective function value (1) & \multicolumn{5}{|c|}{$12,212,402$} \\
\hline Total supply (2) & \multicolumn{5}{|c|}{703,400} \\
\hline Total demand (3) & \multicolumn{5}{|c|}{605,809} \\
\hline RBCs and their locations (4) & 4 & Malatya & Van & Erzurum & Elazı̆ \\
\hline BDCs and their locations (5) & 4 & Malatya & Van & Erzurum & Elazı $\breve{g}$ \\
\hline MBDVs shares (6) & 14 & $2 \mathrm{MBDV}$ & $6 \mathrm{MBDV}$ & $3 \mathrm{MBDV}$ & $3 \mathrm{MBDV}$ \\
\hline
\end{tabular}

\subsection{Sensitivity analysis}

In order to verify the robustness of the solutions provided by the proposed model, we perform a sensitivity analysis 
Table 13 Scenario 6 results

Objective function value (1)

Total supply (2)

Total demand (3)

RBCs and their locations (4)

BDCs and their locations (5)

MBDVs shares (6)
$10,408,228$

781,556

673,121

\begin{tabular}{lllll}
\hline 4 & Malatya & Van & Erzurum & Elazı̆ \\
7 & Malatya & Van, Erciş, Edremit & Erzurum, Erzincan & Elazı̆ \\
14 & $2 \mathrm{MBDV}$ & $5 \mathrm{MBDV}$ & $4 \mathrm{MBDV}$ & $3 \mathrm{MBDV}$
\end{tabular}

Table 14 Scenario 7 results

Table 15 Scenario 8 results

Table 16 Scenario 9 results

Table 17 Scenario 10 results

\begin{tabular}{|c|c|c|c|c|c|}
\hline Objective function value (1) & \multicolumn{5}{|c|}{$10,287,552$} \\
\hline Total supply (2) & \multicolumn{5}{|c|}{312,622} \\
\hline Total demand (3) & \multicolumn{5}{|c|}{269,248} \\
\hline RBCs and their locations (4) & 4 & Malatya & Van & Erzurum & Elazı̆̆ \\
\hline BDCs and their locations (5) & 4 & Malatya & Van & Erzurum & Elazı $\breve{g}$ \\
\hline MBDVs shares (6) & 9 & $1 \mathrm{MBDV}$ & $4 \mathrm{MBDV}$ & $2 \mathrm{MBDV}$ & $2 \mathrm{MBDV}$ \\
\hline
\end{tabular}

\begin{tabular}{|c|c|c|c|c|c|}
\hline Objective function value (1) & \multicolumn{5}{|c|}{$11,558,268$} \\
\hline Total supply (2) & \multicolumn{5}{|c|}{234,467} \\
\hline Total demand (3) & \multicolumn{5}{|c|}{201,936} \\
\hline RBCs and their locations (4) & 4 & Malatya & Van & Erzurum & Elazı $\breve{g}$ \\
\hline BDCs and their locations (5) & 4 & Malatya & Van & Erzurum & Elazığ \\
\hline MBDVs shares (6) & 7 & $2 \mathrm{MBDV}$ & $3 \mathrm{MBDV}$ & $1 \mathrm{MBDV}$ & $1 \mathrm{MBD}$ \\
\hline
\end{tabular}

\begin{tabular}{|c|c|c|c|c|c|}
\hline Objective function value (1) & \multicolumn{5}{|c|}{9570,084} \\
\hline Total supply (2) & \multicolumn{5}{|c|}{156,311} \\
\hline Total demand (3) & \multicolumn{5}{|c|}{134,624} \\
\hline RBCs and their locations (4) & 4 & Malatya & Van & Erzurum & Elazı $\breve{g}$ \\
\hline BDCs and their locations (5) & 4 & Malatya & Van & Erzurum & Elazı $\breve{g}$ \\
\hline MBDVs shares (6) & 5 & $1 \mathrm{MBDV}$ & $2 \mathrm{MBDV}$ & $1 \mathrm{MBDV}$ & $1 \mathrm{MBDV}$ \\
\hline
\end{tabular}

\begin{tabular}{|c|c|c|c|c|c|}
\hline Objective function value (1) & \multicolumn{5}{|c|}{7889,564} \\
\hline Total supply (2) & \multicolumn{5}{|c|}{468,933} \\
\hline Total demand (3) & \multicolumn{5}{|c|}{269,248} \\
\hline RBCs and their locations (4) & 4 & Malatya & Van & Erzurum & Elazı $\breve{g}$ \\
\hline BDCs and their locations (5) & 6 & Malatya, Kars & Van, Ağrı & Erzurum & Elazı $\breve{g}$ \\
\hline MBDVs shares (6) & 4 & - & $2 \mathrm{MBDV}$ & $1 \mathrm{MBDV}$ & $1 \mathrm{MBDV}$ \\
\hline
\end{tabular}


Fig. 4 Obj. function value according to scenarios

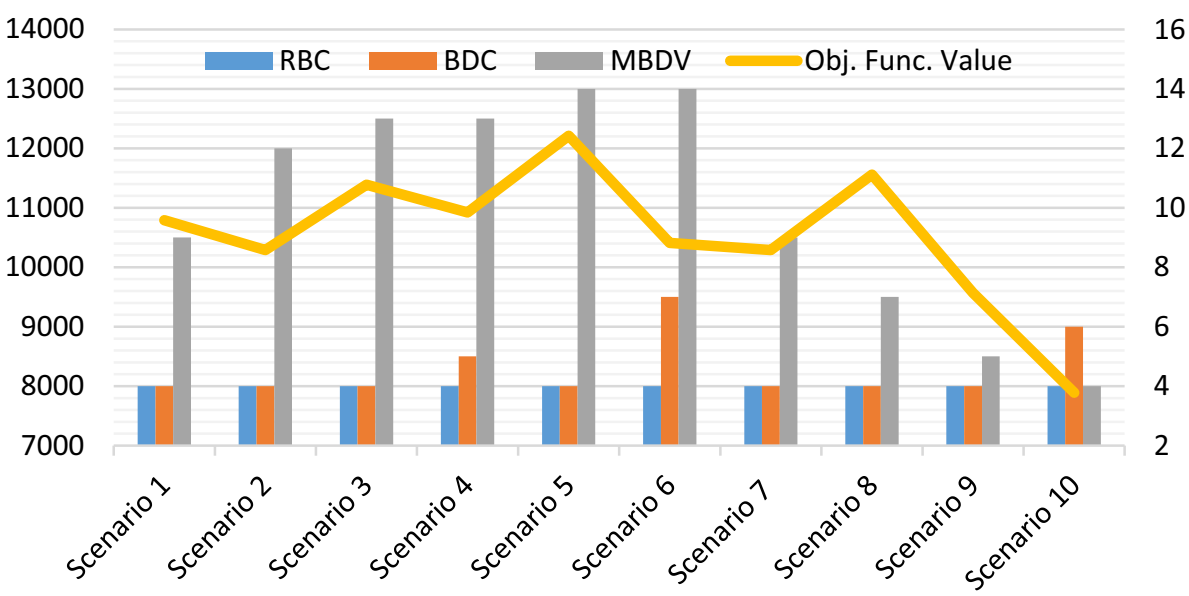

on the basic scenario (scenario 1). For this purpose, the budget constraint (9) of the model is examined. The budget constraint ensures that the annual total operating costs of the facilities opened do not exceed the budget allocated by the Turkish Red Crescent for this region. In our study, the total operating costs $(f)$ that we consider according to each facility include installation costs, operating costs and all related costs associated with the facility. The total allocated budget by the Turkish Red Crescent is determined by considering all investment and operation costs of RBCs, BDCs and MBDVs in the region. This budget value is naturally an estimate and its real value may be slightly different.

If the Turkish Red Crescent's budget $(F)$ that we consider in our main scenario decreases or increases, we would like to analyse the changes in the results. To this end, the total budget has been reduced by $10 \%, 20 \%, 30 \%$ and increased by $10 \%, 20 \%, 30 \%$, and the results are reported below. (Tables 18, 19, 20, 21, 22 and 23).

When the results obtained in the above tables and scenario 1 results are compared, it is seen that increasing the total budget does not cause any significant changes in the supply chain management system. Unlike the scenario 1 results, only one more MBDV unit is used. Responsiveness of the objective function to the budget decrease may also be attributed to the solver's performance in the limited computation time. Table 22 also indicates a slight increase in the objective function as a result of an increase in the budget level which is a contradiction and can only be attributed to the solver's performance. Therefore, an \%100 accurate and more detailed sensitivity analysis is not possible as the performance of the solver is limited. At this point, alternatives obtained and reported in Tables 18, 19, 20, 21, 22 and 23 can be offered to the Red Crescent and the managers who is in charge may use them for comparison purposes, while deciding the investments. In addition, with the savings to be obtained from the current budget, more and different investment proposals can be made. We also observe from tables that decreasing the budget gradually forces the supply chain to reach and serve more cities and settlements using MBDVs. This is because MBDVs are shared between RBCs in a different combination and they travel more for blood donations while the positions of RBCs and BDCs remain the same. This implies that while the affordability of demand is $100 \%$, a more effective structure emerges. It should not be forgotten that all these variations may vary according to the estimated supply and demand amount. For example, COVID-19 pandemic has caused $30 \%$ reduction in blood donation in 2020. Therefore, the Red Crescent's supply chain management should have an agile and harmonious structure in order to response possible rapid changes in supply and demand values. Our sensitivity analysis indicates that the model offered in this study may help Red Crescent to construct a more robust blood supply chain that is capable of adapting changes in design parameters.

\section{Conclusions}

The collection, processing and distribution of blood and/or blood products effectively and efficiently are very important functions performed by the blood supply chains in the health system. In this study, a mathematical model is proposed to provide optimal network design and planning of the blood supply chain. As in many similar studies in the literature, the blood supply chain examined does not consist solely of blood banks and transfusion centers (hospitals, health institutions, etc.). The supply chain we examine belongs to the Turkish Red Crescent, and it has four echelons; RBCs, BDCs, MBDVs and supply/demand points. In this complex structure, important decisions such as determining the location of the facilities, determining the route that mobile units should follow are to be made.

In the proposed model, the objective function is designed to minimize the lengths between the units that 
Table 18 Results of the total budget was reduced by $\% 10$

Table 19 Results of the total budget was reduced by $\% 20$

Table 20 Results of the total budget was reduced by $\% 30$

Table 21 Results of the total budget was increased by $\% 10$

Table 22 Results of the total budget was increased by $\% 20$

\begin{tabular}{|c|c|c|c|c|c|}
\hline Objective function value (1) & \multicolumn{5}{|c|}{$10,118,844$} \\
\hline Total supply (2) & \multicolumn{5}{|c|}{390,778} \\
\hline Total demand (3) & \multicolumn{5}{|c|}{336,560} \\
\hline RBCs and their locations (4) & 4 & Malatya & Van & Erzurum & Elazığ \\
\hline BDCs and their locations (5) & 4 & Malatya & Van & Erzurum & Elazığ \\
\hline MBDVs shares (6) & 10 & $2 \mathrm{MBDV}$ & $4 \mathrm{MBDV}$ & $2 \mathrm{MBDV}$ & $2 \mathrm{MBDV}$ \\
\hline
\end{tabular}

Objective function value (1)

Total supply (2)

$10,118,844$

Total demand (3)

RBCs and their locations (4)

BDCs and their locations (5)

MBDVs shares (6)

390,778

336,560

$4 \quad$ Malatya $\quad$ Van $\quad$ Erzurum $\quad$ Elazığ

4 Malatya Van Erzurum Elazı

$102 \mathrm{MBDV} 4 \mathrm{MBDV} 2 \mathrm{MBDV} 2 \mathrm{MBDV}$

Objective function value (1)

Total supply (2)

Total demand (3)

RBCs and their locations (4)

BDCs and their locations (5)

MBDVs shares (6)

\section{$10,118,844$}

390,778

336,560

\begin{tabular}{|c|c|c|c|c|}
\hline 4 & Malatya & Van & Erzurum & Elazı̆̆ \\
\hline 4 & Malatya & Van & Erzurum & Elazı $\breve{g}$ \\
\hline 10 & $2 \mathrm{MBDV}$ & $4 \mathrm{MBDV}$ & $2 \mathrm{MBDV}$ & MBI \\
\hline
\end{tabular}

\begin{tabular}{|c|c|c|c|c|c|}
\hline Objective function value (1) & \multicolumn{5}{|c|}{9784,08} \\
\hline Total supply (2) & \multicolumn{5}{|c|}{390,778} \\
\hline Total demand (3) & \multicolumn{5}{|c|}{336,560} \\
\hline RBCs and their locations (4) & 4 & Malatya & Van & Erzurum & Elazığ \\
\hline BDCs and their locations (5) & 4 & Malatya & Van & Erzurum & Elazı $\breve{g}$ \\
\hline MBDVs shares (6) & 10 & $2 \mathrm{MBDV}$ & $4 \mathrm{MBDV}$ & $2 \mathrm{MBDV}$ & $2 \mathrm{MBDV}$ \\
\hline
\end{tabular}

\begin{tabular}{|c|c|c|c|c|c|}
\hline Objective function value (1) & \multicolumn{5}{|c|}{$11,104,164$} \\
\hline Total supply (2) & \multicolumn{5}{|c|}{390,778} \\
\hline Total demand (3) & \multicolumn{5}{|c|}{336,560} \\
\hline RBCs and their locations (4) & 4 & Malatya & Van & Erzurum & Elazığ \\
\hline BDCs and their locations (5) & 4 & Malatya & Van & Erzurum & Elazı $\breve{g}$ \\
\hline MBDVs shares (6) & 10 & $1 \mathrm{MBDV}$ & $4 \mathrm{MBDV}$ & $3 \mathrm{MBDV}$ & $2 \mathrm{MBDV}$ \\
\hline
\end{tabular}

make up the blood supply chain and the length of the mobile unit routes. The objective function indirectly minimizes the transport time and cost, and indirectly improves the blood products' shelf lives. These goals are combined in an objective function by multiplying different priority coefficients found by the help of analytical hierarchy process. 
Table 23 Results of the total budget was increased by $\% 30$

\begin{tabular}{|c|c|c|c|c|c|}
\hline Objective function value (1) & \multicolumn{5}{|c|}{9251,232} \\
\hline Total supply (2) & \multicolumn{5}{|c|}{390,778} \\
\hline Total demand (3) & \multicolumn{5}{|c|}{336,560} \\
\hline RBCs and their locations (4) & 4 & Malatya & Van & Erzurum & Elazığ \\
\hline BDCs and their locations (5) & 4 & Malatya & Van & Erzurum & Elazı̆̆ \\
\hline MBDVs shares (6) & 9 & $1 \mathrm{MBDV}$ & $4 \mathrm{MBDV}$ & $2 \mathrm{MBDV}$ & $2 \mathrm{MBDV}$ \\
\hline
\end{tabular}

The Turkish Red Crescent blood supply chain in the Eastern region of Turkey is discussed. For this purpose, in order to measure the effectiveness of the current system, the relevant variables in the proposed model are fixed by the ones from the existing scenario. One may observe that the offered model produces more effective supply chains than the existing ones.

In future studies, we will examine the situation of blood supply chain for Turkey as a whole. Thus, the size of the problem will increase. It will probably consume an excessive amount of the time and a meta-heuristic algorithm will probably be required for its solution. Hence a more efficient blood supply chain design will be targeted for the whole country. Another future research direction is to extend the model to take varying shelf lives of the blood products and inventory decisions of the blood products into account.

Funding No funding is provided for the preparation of manuscript.

\section{Compliance with ethical standards}

Conflict of interest Authors İlker Karadağ, M. Emre Keskin and Vecihi Yiğit declare that they have no conflict of interest.

Ethical approval This article does not contain any studies with human participants or animals performed by any of the authors.

\section{References}

Abdulwahab U, Wahab MIM (2014) Approximate dynamic programming modelling for a typical blood platelet bank. Comput Ind Eng 78:259-270

Arvan M, Tavakkoli-Moghaddam R, Abdollahi M (2015) Designing a bi-objective, multi-product supply chain network for blood supply. Uncertain Supply Chain Manage 3:57-68

Beliën J, Forcé H (2012) Supply chain management of blood products: a literature review. Eur J Oper Res 217:1-16

Blake J, McTaggart K, Hardy M (2015) Modelling a blood distribution network in the prairies with a generic simulation framework. Inf Syst Operat Res 53(4):194-210

Bruno G, Diglio A, Piccolo C, Cannavacciuolo L (2019) Territorial reorganization of regional blood management systems: Evidences from an Italian case study. Omega 89:54-70
Chen L, Peng J, Liu Z, Zhao R (2017) Pricing and effort decisions for a supply chain with uncertain information. Int $J$ Prod Res 55(1):264-284

Clay NM, Abbasi B, Eberhard A, Hearne J (2018) On the volatility of blood inventories. Int Trans Operat Res 25:215-242

Çetin E, Sarul LS (2009) A blood bank location model: a multi objective approach. Euro J Pure Appl Math 2(1):112-124

Diabat A, Jabbarzadeh A, Khosrojerdi A (2019) A perishable product supply chain network design problem with reliability and disruption considerations. Int J Prod Econ 212:125-138

Dillon M, Oliveira F, Abbasi B (2017) A two-stage stochastic programming model for inventory management in the blood supply chain. Int J Prod Econ 187:27-41

Duan Q, Liao TW (2014) Optimization of blood supply chain with shortened shelf lives and ABO compatibility. Int J Prod Econ 153:113-129

Elalouf A, Tsadikovich D, Hovav S (2018) Optimization of blood sample collection with timing and quality constraints. Int Trans Operat Res 25:191-214

Ensafian H, Yaghoubi S, Yazdi MM (2017) Raising quality and safety of platelet transfusion services in a patient-based integrated supply chain under uncertainty. Comput Chem Eng 106:355-372

Ensafian H, Yaghoubi S (2017) Robust optimization model for integrated procurement production and distribution in platelet supply chain. Transp Res Part E 103:32-55

Eskandari-Khanghahi M, Tavakkoli-Moghaddam R, Taleizadeh AA, Amin SH (2018) Designing and optimizing a sustainable supply chain network for a blood platelet bank under uncertainty. Eng Appl Artif Intell 71:236-250

Fahimnia B, Jabbarzadeh A, Ghavamifar A, Bell M (2017) Supply chain design for efficient and effective blood supply in disasters. Int J Prod Econ 183:700-709

Fazli-Khalaf M, Khalilpourazari S, Mohammadi M (2019) Mixed robust possibilistic flexible chance constraint optimization model for emergency blood supply chain network design. Ann Oper Res 283:1079-1109

Ghandforoush P, Sen TK (2010) A DSS to manage production supply chain for regional blood centers. Decis Support Syst 50:32-42

Glasgow SM, Perkins ZB, Tai NRM, Brohi K, Vasilakis C (2018) Development of a discrete event simulation model for evaluating strategies of red blood cell provision following mass casualty events. Eur J Oper Res 270:362-374

Gunpinar S, Centeno G (2016) An integer programming approach to the bloodmobile routing problem. Transp Res Part E 86:94-115

Gunpinar S, Centeno G (2015) Stochastic integer programming models for reducing wastages and shortages of blood products at hospitals. Comput Oper Res 54:129-141

Gurobi Optimization (2019) Gurobi Optimizer Reference Manual [online] http://www.gurobi.com (accessed 18 November 2019)

Hamdan B, Diabat A (2020a) Robust design of blood supply chains under risk of disruptions using Lagrangian relaxation. Transp Res Part E 134:101764 
Hamdan B, Diabat A (2020b) Predicting solutions of large-scale optimization problems via machine learning: a case study in blood supply chain management. Comput Oper Res 119:104941

Hamdan B, Diabat A (2019) A two-stage multi-echelon stochastic blood supply chain problem. Comput Oper Res 101:130-143

Haghjoo N, Moghaddam RT, Moghaddam HS, Rahimi Y (2020) Reliable blood supply chain network design with facility disruption: a real-world application. Eng Appl Artif Intell. https://doi.org/10.1016/j.engappai.2020.103493

Heidari-Fathian H, Pasandideh SHR (2018) Green-blood supply chain network design: Robust optimization, bounded objective function \& Lagrangian relaxation. Comput Ind Eng 122:95-105

Hosseinifard Z, Abbasi B (2018) The inventory centralization impacts on sustainability of the blood supply chain. Comput Oper Res 89:206-212

Hosseinifard Z, Abbasi B, Clay NM (2020) Post disaster volatility of blood donations in an unsteady blood supply chain. Decis Sci 51(2):255-281

Hosseini-Motlagh SM, Samani MRG, Homaei S (2020) Blood supply chain management: robust optimization, disruption risk and blood group compatibility (a real-life case). J Ambient Intell Human Comput 11:1085-1104

Jabbarzadeh A, Fahimnia B, Seuring S (2014) Dynamic supply chain network design for the supply of blood in disasters: A robust model with real world application. Transp Res Part E 70:225-244

Jafarkhan F, Yaghoubi S (2018) An efficient solution method for the flexible and robust inventory-routing of red blood cells. Comput Ind Eng 117:191-206

Karaesmen, I.Z., Scheller-Wolf, A., Deniz, B., (2011) Managing perishable and aging inventories: review and future research directions. Planning Production and Inventories in the Extended Enterprise Springer 393-436

Khalilpourazari S, Khamseh AA (2019) Bi-objective emergency blood supply chain network design in earthquake considering earthquake magnitude: a comprehensive study with real world application. Ann Oper Res 283:355-393

Lowalekar H, Ravichandran N (2017) A combined age-and-stockbased policy for ordering blood units in hospital blood banks. Int Trans Operat Res 24:1561-1586

Masoumi AH, Yu M, Nagurney A (2017) Mergers and acquisitions in blood banking systems: a supply chain network approach. Int J Prod Econ 193:406-421

Nagurney A, Masoumi AH, Yu M (2012) Supply chain network operations management of a blood banking system with cost and risk minimization. CMS 9:205-231

Nahmias S (1982) Perishable Inventory Theory: a Review. Operat Res 30(4):680-708. https://doi.org/10.2307/170438

Najafi M, Ahmadi A, Zolfagharinia H (2017) Blood inventory management in hospitals: considering supply and demand uncertainty and blood transshipment possibility. Operat Res Heath Care 15:43-56

Or I, Pierskalla W (1979) A Transportation Location-Allocation Model for Regional Blood Banking. IIE Trans 11(2):86-95

Osorio AF, Brailsford S, Smith HK, Forero-Matiz SP, CamachoRodriguez BA (2017) Simulation-optimization model for production planning in the blood supply chain. Health Care Manage Sci 20:548-564

Osorio AF, Brailsford S, Smith HK (2015) A structured review of quantitative models in the blood supply chain: a taxonomic framework for decision-making. Int $\mathrm{J}$ Prod Res 53(24):7191-7212
Pierskalla WP (2004) Supply chain management of blood banks Operations Research and Health Care: A. In: Brandeau ML, Sainfort F, Pierskalla WP (eds) Handbook of Methods and Applications. Kluwer Academic Publishers, Boston, MA, pp $103-145$

Pirabán A, Guerrero WJ, Labadie N (2019) Survey on blood supply chain management: Models and methods. Comput Oper Res 112:104756

Prastacos GB (1984) Blood inventory management: an overview of theory and practice. Manage Sci 30(7):777-800

Rahmani D (2019) Designing a robust and dynamic network for the emergency blood supply chain with risk of disruptions. Ann Oper Res 283:613-641

Ramezanian R, Behboodi Z (2017) Blood supply chain network design under uncertainties in supply and demand considering social aspects. Transp Res Part E 104:69-82

Saaty TL (1990) How to make a decision: analytic hierarchy process. Eur J Oper Res 48(1):9-26

Salehi F, Mahootchi M, Husseini SMM (2019) Developing a robust stochastic model for designing a blood supply chain network in a crisis: a possible earthquake in Tehran. Ann Oper Res 283:679-703

Samani MRG, Torabi SA, Hosseini-Motlagh SM (2018) Integrated blood supply chain planning for disaster relief. Int J Disas Risk Reduct 27:168-188

Samani MRG, Hosseini-Motlagh SM (2019) An enhanced procedure for managing blood supply chain under disruptions and uncertainties. Ann Oper Res 283(1-2):1413-1462

Sharma B, Ramkumar M, Subramanian N, Malhotra B (2019) Dynamic temporary blood facility location-allocation during and post-disaster periods. Ann Oper Res 283:705-736

Şahin G, Süral H, Meral S (2007) Locational analysis for regionalization of Turkish Red Crescent blood services. Comput Oper Res 34:692-704

Şahinyazan FG, Kara BY, Taner MR (2015) Selective vehicle routing for a mobile blood donation system. Eur J Oper Res 245:22-34

Wang C, Chen S (2020) (2020) A distributionally robust optimization for blood supply chain network considering disasters. Transp Res Part E 134:101840

Wang KM, Ma ZJ (2015) Age-based policy for blood transshipment during blood shortage. Transp Res Part E 80:166-183

Wang R, Nan G, Chen L, Li M (2020) Channel integration choices and pricing strategies for competing dual-channel retailers. IEEE Trans Eng Manage. https://doi.org/10.1109/TEM.2020.3007347

Xiao Q, Chen L, Xie M, Wang C (2020) Optimal contract design in sustainable supply chain: interactive impacts of fairness concern and overconfidence. J Operat Res Soc. https://doi.org/10.1080/ 01605682.2020.1727784

Zahiri B, Torabi SA, Mohammadi M, Aghabegloo M (2018) A multistage stochastic programming approach for blood supply chain planning. Comput Ind Eng 122:1-14

Zahiri B, Pishvaee MS (2017) Blood supply chain network design considering blood group compatibility under uncertainty. Int $\mathbf{J}$ Prod Res 55(7):2013-2033

Zahiri B, Torabi SA, Mousazadeh M, Mansouri SA (2015) Blood collection management: methodology and application. Appl Math Model 39:7680-7696

Publisher's Note Springer Nature remains neutral with regard to jurisdictional claims in published maps and institutional affiliations. 